\title{
Retraction
}

\section{Retracted: Sublinear Expectation Nonlinear Regression for the Financial Risk Measurement and Management}

\author{
Discrete Dynamics in Nature and Society \\ Received 14 November 2013; Accepted 14 November 2013 \\ Copyright (C) 2013 Discrete Dynamics in Nature and Society. This is an open access article distributed under the Creative Commons \\ Attribution License, which permits unrestricted use, distribution, and reproduction in any medium, provided the original work is \\ properly cited.
}

The paper titled "Sublinear Expectation Nonlinear Regression for the Financial Risk Measurement and Management" [1], published in Discrete Dynamics in Nature and Society, has been retracted as it was submitted for publication by Yunquan Song without the knowledge and approval of the coauthor Lu Lin.

\section{References}

[1] Y. Song and L. Lin, "Sublinear expectation nonlinear regression for the financial risk measurement and management," Discrete Dynamics in Nature and Society, vol. 2013, Article ID 398750, 10 pages, 2013. 